\title{
Calibration and Flight Results for the Ares I-X 5-hole Probe
}

Joel F. Campbell and Jay M. Brandon

NASA Langley Research Center, MS 488

Hampton, VA 23681

joel.f.campbell@nasa.gov

Flight and calibration results are presented for the Ares I-X 5-hole probe. The probe is calibrated by using a combination of wind tunnel, CFD, and other numerical modeling techniques. This is then applied to the probe flight data and comparisons are made between the vanes and 5-hole probe. Using this and other data it is shown the probe was corrupted by water rendering that measurement unreliable.

\section{Nomenclature}

Pseudo static pressure (psi)

Pseudo dynamic pressure (psi)

$\bar{P}_{25}$

Free stream Mach number

$q$

Pitch angle (deg)

$\mathrm{M}$

Yaw angle (deg)

$\alpha$

Pressure at port $\mathrm{n}(1 \leq n \leq 6)$

$\beta$

Free stream static pressure

$P_{n}$

Pitch angle coefficient

$P_{S}$

Yaw angle coefficient

$C_{\alpha}$

Mach coefficient

$C_{\beta}$

Pressure coefficient at port $\mathrm{n}$

$C_{M}$

$C_{P n}$

Average pressure coefficient for ports 2-5 $\quad C_{P 25}$

\section{Introduction}

Ares I-X was successfully launched on October 28, 2009 (see Figure 1) and was a design concept demonstrator in the Ares I program. The Ares I first stage is a single, fivesegment reusable solid rocket booster derived from the Space Shuttle Program's reusable solid rocket motor. In the Ares I-X program only 4 of the 5 segments held propellant and the fifth contained instrumentation. Unlike the Ares I, the second stage of the Ares I-X was unpowered, but was otherwise was similar in shape, mass, and size. With more than 700 sensors and 3 video cameras, it was also one of the most heavily instrumented rockets ever flown and was designed to give engineers an opportunity to verify their control design and analysis tools, and simulations of the Ares I, which is designed for human spaceflight. 


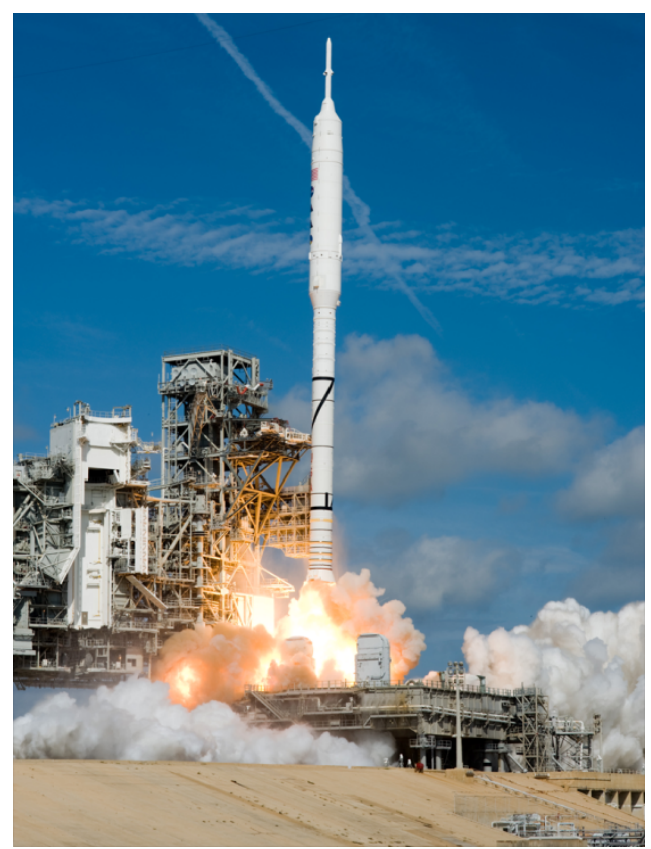

Figure 1. Ares I-X launch.

Sitting on the top of the Ares I-X was the 5-hole probe (Figure 2). This 5-hole probe was originally conceived of by a NASA LaRC engineer, who later left the project, in collaboration with a Lockheed-Martin subcontractor in the 2007 time frame. The project was then taken over and managed by Marshall Space Flight Center.

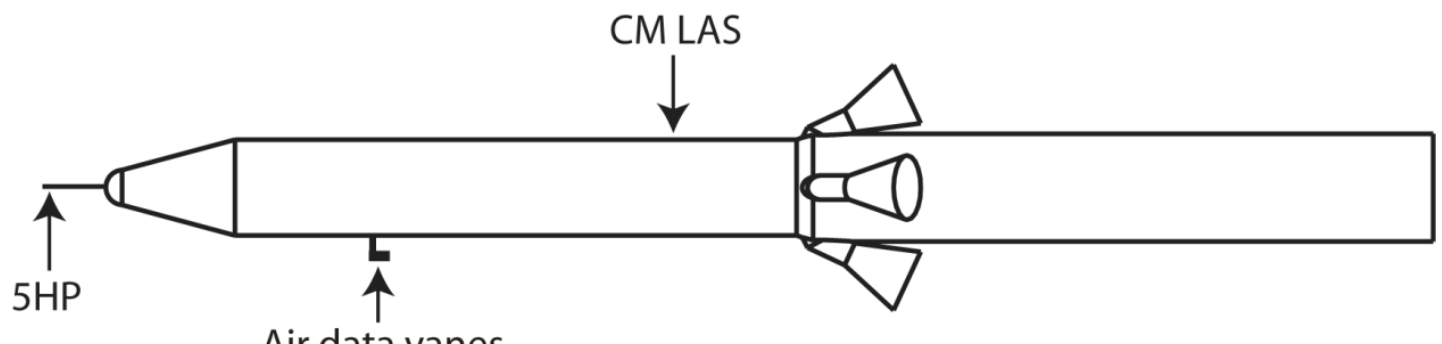

Air data vanes

Figure 2. CM LAS/vane/5-hole probe assembly

The probe's function is to measure angle of attack and Mach number for the Ares I-X rocket during flight by direct measurement of the calibrated pressures at the 5 ports, static ring, and plenum. Additionally, angle of attack and sideslip vanes were mounted on the LAS for backup measurements. Due to the complex aerodynamics further back on the LAS, the measurements of the vanes were not expected to be of high quality. The vanes did not undergo any aerodynamic calibration testing, so CFD studies were conducted to develop upwash corrections to apply to the measured vane positions to determine an estimate of angle of attack and sideslip. Since there was no testing of the actual vanes, the actual vane performance (float angles vs. Mach, for instance) are not known. The probe details are shown in Figure 3, and the plumbing of the ports is shown in Figure 4. 

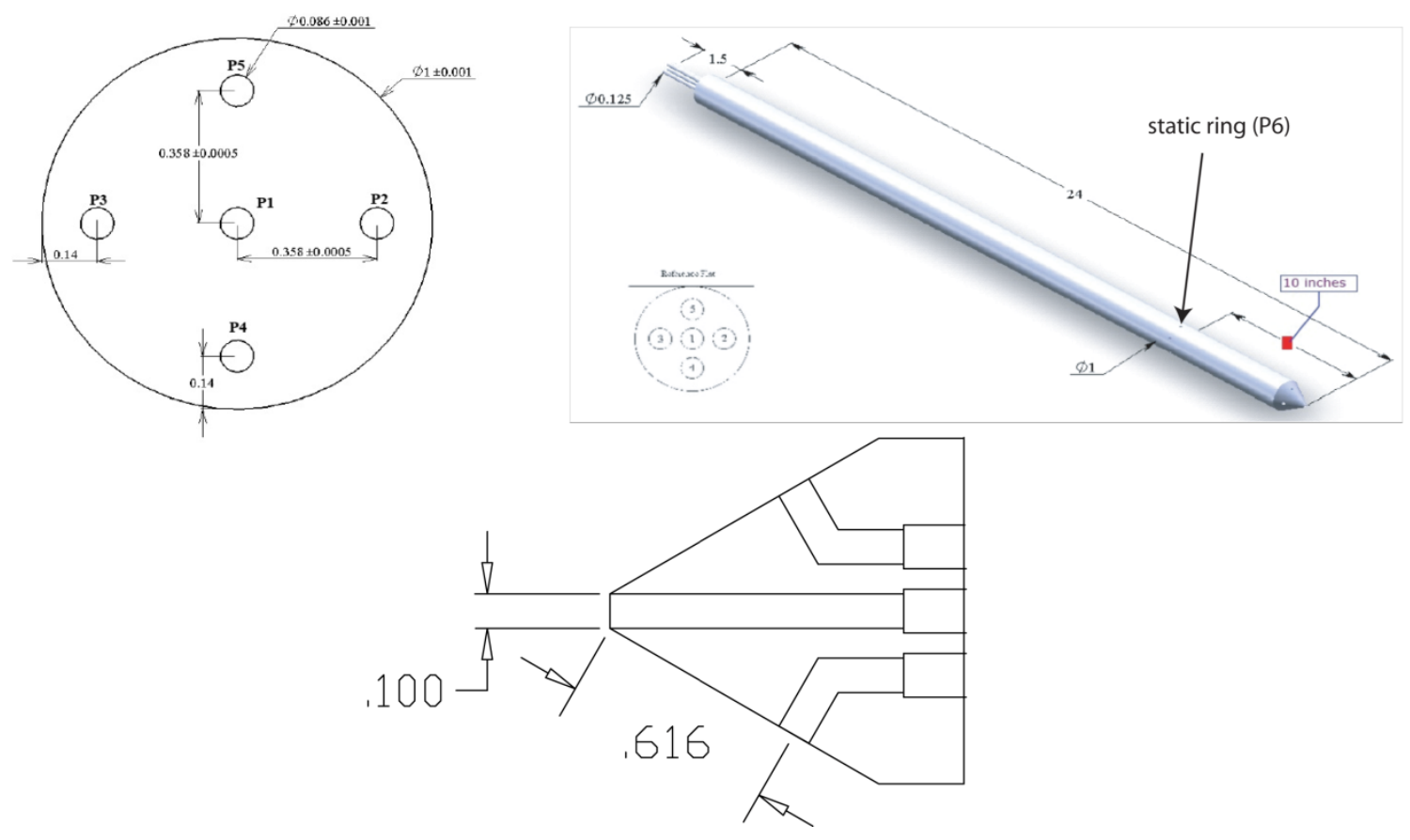

Figure 3. Port location for the 5-hole probe.

The tip of the probe is conical with a 30 degree half angle. The transducers on ports 1-6 measure the differential pressures between those ports and the plenum. Port 7 is the plenum, which is vented to the LAS and upper stage. The pressures are then digitized at 12 bits resolution on the flight digital acquisition system. 


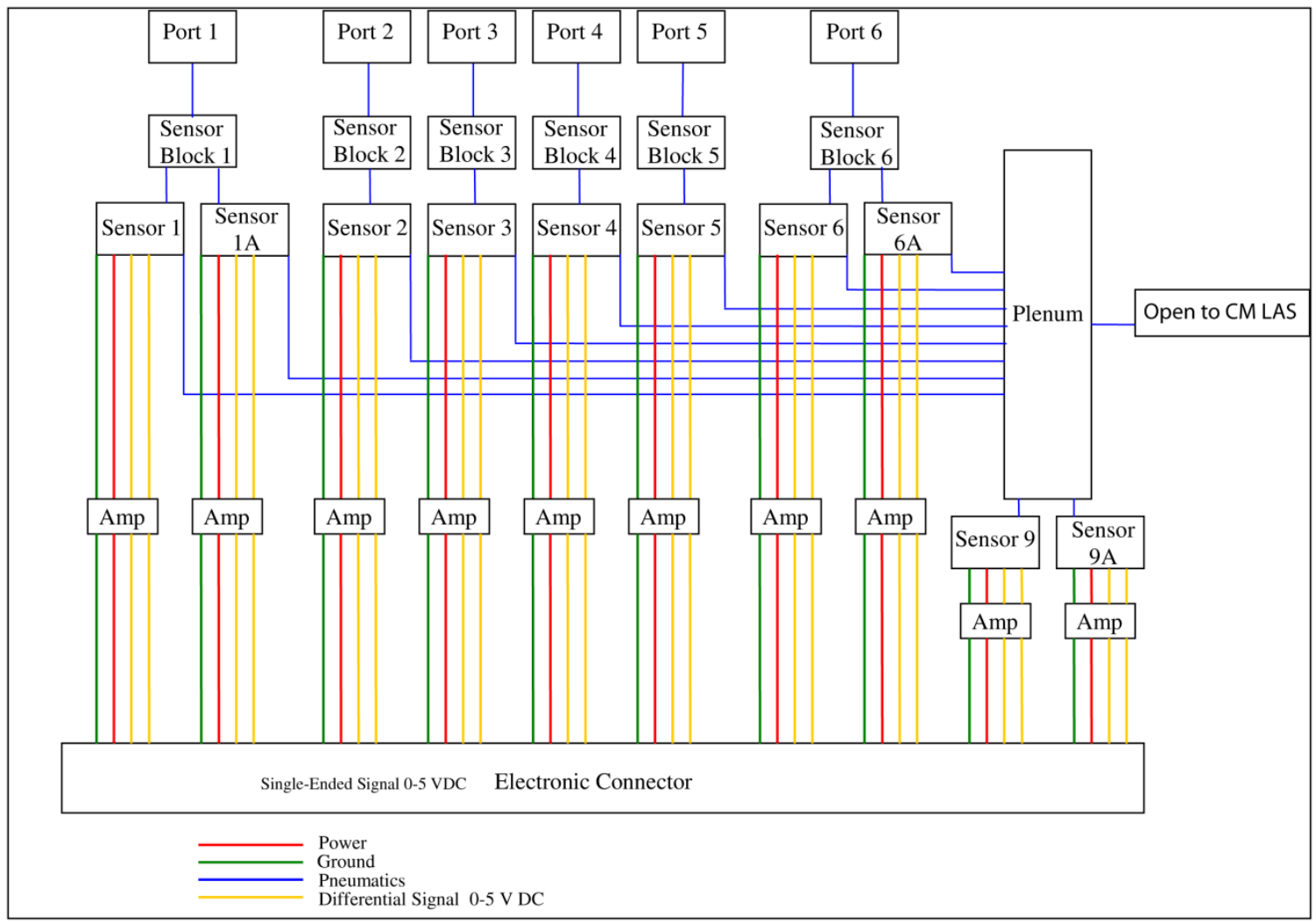

Figure 4. Plumbing and electrical configuration for the 5-hole probe.

Two unfortunate things happened that worked together to make use of the 5HP data problematic. The first problem occurred during the wind tunnel testing to develop calibrations for the probe. The second problem was that during the launch campaign, the probe was exposed to rain.

The 5HP calibration tests were conducted in the Boeing Polysonic Wind Tunnel (PSWT). The PSWT is a blow-down wind tunnel with a test section size of approximately $4 \mathrm{ft}$ by 4 $\mathrm{ft}$. For transonic tests $(0.45-1.60 \mathrm{Mach})$, the test section uses a porous wall, and for supersonic tests, it uses a solid wall test section. The hardware tested in the wind tunnel included the probe and the nose cap onto which the probe is mounted to on the rocket. The nosecap at the base of the probe was rather large (diameter of approximately 12.5"), and made it difficult to conduct wind tunnel tests at high supersonic Mach numbers due to choking problems in the tunnel. In addition, the subcontractor had concerns about over pressurization of the transducers and potentially damaging them at higher Mach numbers. As a result of these two testing issues, no calibration data were obtained above Mach 3 . Without the higher Mach number wind tunnel data, part of the calibration needed to be done by simulation. CFD has been used in the past[1] with positive results. In the present case we used a combination of older numerical techniques, which were verified by CFD (USM3D). In the case of the static port data, however, CFD and other flow calculation techniques that were attempted were not successful at computing observed data from the 
wind tunnel. As a result the calibration of the static port was not successful, and no results from that are presented here.

The other unfortunate event that occurred making the probe data problematic is that the probe was exposed to a rainstorm. Condensation was also a potential issue. To save cost, keep systems simple to improve overall safety of the vehicle, and to utilize available COTS 5HP hardware, the probe selected was simple - no heating or drains were included. This was deemed acceptable due to the fact that the test flight was a one-time event, and the weather would be very good to permit a launch. A probe cover was designed to keep water and other foreign objects out of the probe, however instead of a cover that came off at launch, for launch processing simplification reasons, it was decided to manually remove the cover, necessitating its removal before evacuating all personnel from the launch pad. Additionally, since the Ares I-X is much taller than the Space Shuttle, there was no access to the top of the vehicle to re-install the cover once it had been removed. During the launch campaign, the probe cover was removed prior to attempting a launch. Due to various problems such as range intrusions, cloud cover and triboelectrification issues, and then winds, the launch was scrubbed on the first day. Since the probe cover had been removed and there was no access available to the top of the vehicle, the probe was left uncovered overnight during strong thunderstorms that developed through most of the night. The launch was successful the following day. Immediate post-flight quick looks showed the pressures measured from the probe varying (see Figure A1), so it was hoped that the probe data would be reliable even though it had sat through rain and the thunderstorms the night before the launch.

\section{Probe Calibration Procedure}

The following quantities are defined to be used in reducing wind tunnel (or calculated) measurements from the probe.

$$
\begin{array}{ll}
\text { Pseudo static pressure } & \bar{P}_{25}=\frac{1}{4}\left(P_{2}+P_{3}+P_{4}+P_{5}\right), \\
\text { Pseudo dynamic pressure } & \bar{q}=P_{1}-\bar{P}_{25}, \\
\text { Pitch angle coefficient } & C_{\alpha}=\frac{P_{4}-P_{5}}{\bar{q}}, \\
\text { Yaw angle coefficient } & C_{\beta}=\frac{P_{2}-P_{3}}{\bar{q}}, \\
\text { Mach coefficient } & C_{M}=\frac{\bar{q}}{P_{1}+P_{7}},
\end{array}
$$

Using an approach similar to Gonsalez et al [2], the pitch and yaw angle of attack can be calculated from the following polynomial 


$$
\begin{aligned}
& \alpha=\alpha_{0}+k_{1 \alpha} C_{\alpha}+k_{2 \alpha} C_{\beta}+k_{3 \alpha} C_{M}+k_{4 \alpha} C_{M}^{2}+k_{5 \alpha} C_{M} C_{\alpha}+k_{6 \alpha} C_{M} C_{\beta}+\ldots \\
& \beta=\beta_{0}+k_{1 \beta} C_{\alpha}+k_{2 \beta} C_{\beta}+k_{3 \beta} C_{M}+k_{4 \beta} C_{M}^{2}+k_{5 \beta} C_{M} C_{\alpha}+k_{6 \beta} C_{M} C_{\beta}+\ldots
\end{aligned}
$$

The free stream total and static pressure coefficients can be calculated from

$$
M=M_{0}+k_{1 M} C_{\alpha}+k_{2 \alpha} C_{\beta}+k_{3 M} C_{M}+k_{4 M} C_{M}^{2}+k_{5 M} C_{M} C_{\alpha}+k_{6 M} C_{M} C_{\beta}+\ldots
$$

Equation 8 differs from that used by Gonsalez et al [2] because for the current calibration data, static pressure measurements from $\mathrm{P}_{6}$ (the static pressure ring of ports) were unusable.

The regression equation coefficients ( $\mathrm{k}$ 's) from equations 6-8 were determined using a least squares fit to the wind tunnel and calculated data as a calibration source. The least squares polynomial fit order is: first order in $C_{\alpha}$ and $C_{\beta}$; and tenth order in $C_{M}$. The result of the fit calibration data determines the coefficients. The air data can then be determined directly from the flight pressures transformed into $C_{\alpha}, C_{\beta}$, and $C_{M}$.

\section{Comparison of wind tunnel results with theory and CFD}

The general procedure for calibration is given in the previous section and is very straightforward provided there are no issues with the data. Because of the issues of choking the tunnel flow supersonically and transducer ranges mentioned previously, calibration data was not provided past Mach 3 and the subcontractor recommended using direct extrapolation. High quality CFD data, which was not available to the subcontractor at the time, or other modeling techniques should provide a more accurate calibration so flow modeling techniques were used to fill out the calibration at the higher Mach numbers.

The subcontractor's experimental procedure was to calculate pressures from the transducer data that was taken by sweeping from $\alpha=-10$ deg to +10 deg while holding $\beta=0$, and then holding $\alpha=0$ and sweeping $\beta$. This assumes a linear relationship without non-linear cross coupling and is only valid for small angles.

One convenient quantity to calculate is the pressure coefficient. To express a port pressure in terms the pressure coefficient we write

$$
C_{P}=\frac{\frac{P}{P_{S}}-1}{\frac{1}{2} \gamma M^{2}} .
$$


Here, $\mathrm{P}_{\mathrm{S}}$ is the free stream static pressure, $\mathrm{P}$ is the total pressure at the surface, $\mathrm{M}$ is the free stream Mach number and $\gamma$ is the heat capacity ratio.

\section{Pressure coefficient of tip}

The tip of the probe can be modeled analytically to a high accuracy as a blunt surface and using normal shock theory [3]. Alternatively, one may use the Rayleigh pitot equation [4, 5] in combination with Equation 9. In either case, the expression for the total pressure at the tip of the probe is,

$$
C_{P 1}=\frac{2}{\gamma M^{2}}\left[\left(\frac{(\gamma+1)^{2} M^{2}}{4 \gamma M^{2}-2(\gamma-1)}\right)^{\frac{\gamma}{\gamma-1}} \frac{1-\gamma+2 \gamma M^{2}}{\gamma+1}-1\right]
$$

This applies to the tip of any probe at zero angle of attack whether it is conical or not, provided it has a port at the tip and $M>1$. Although this can also be computed using CFD, the CFD results tend to produce anomalous results beginning around Mach 1.5. This is where the shock front goes from a transition of detached to attached. As a result the CFD calculation becomes very sensitive to how the grid is setup and tends to give inaccurate results with a different trend above approximately Mach 1.5.

Figure 5 shows a comparison between CFD, wind tunnel testing, and the theoretical curve represented by Equation 10. Here we see the CFD matches almost identically until around Mach 1.5.

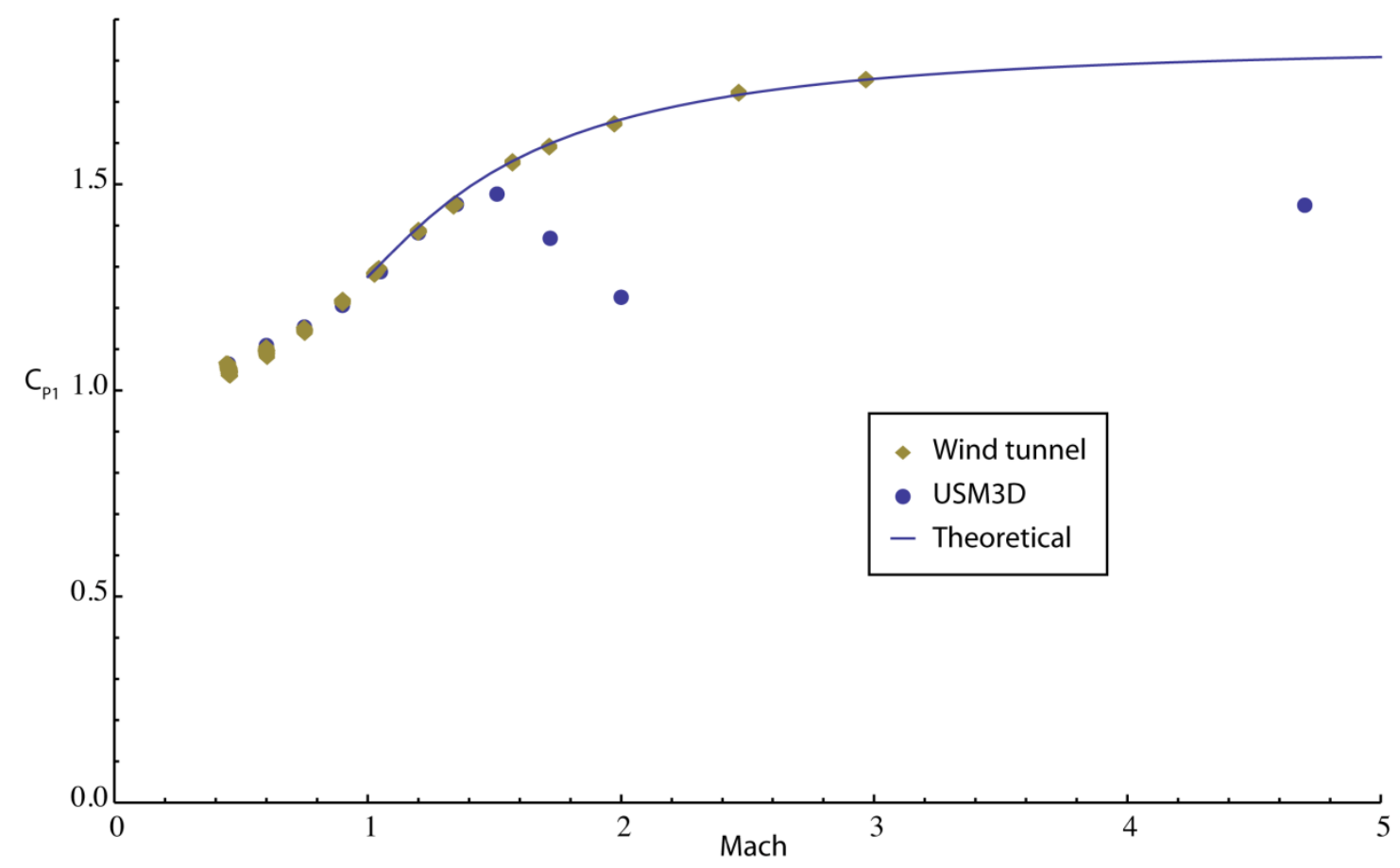


Figure 5. Comparison of probe tip pressure coefficient estimates from wind tunnel test, CFD, and theoretical result represented by Equation 10.

\section{Pressure coefficient of ports 2-5 at 0 angle of attack}

As in the previous example we plot the pressure coefficient at 0 angle of incidence.

Figure 6 is the result of that plot. Unlike the previous example, the CFD curve is more continuous.

In order to compare ports 2-5 with theory and CFD we average ports 2-5 together from the wind tunnel readings and process the entire wind tunnel data for all angles of attack from -10 deg to $+10 \mathrm{deg}$. We then compare this to CFD and the Taylor-Macoll solution for conical flow [6]. There is a slight variation of this average with respect to angle, but the comparison is still valid as this variation is small.

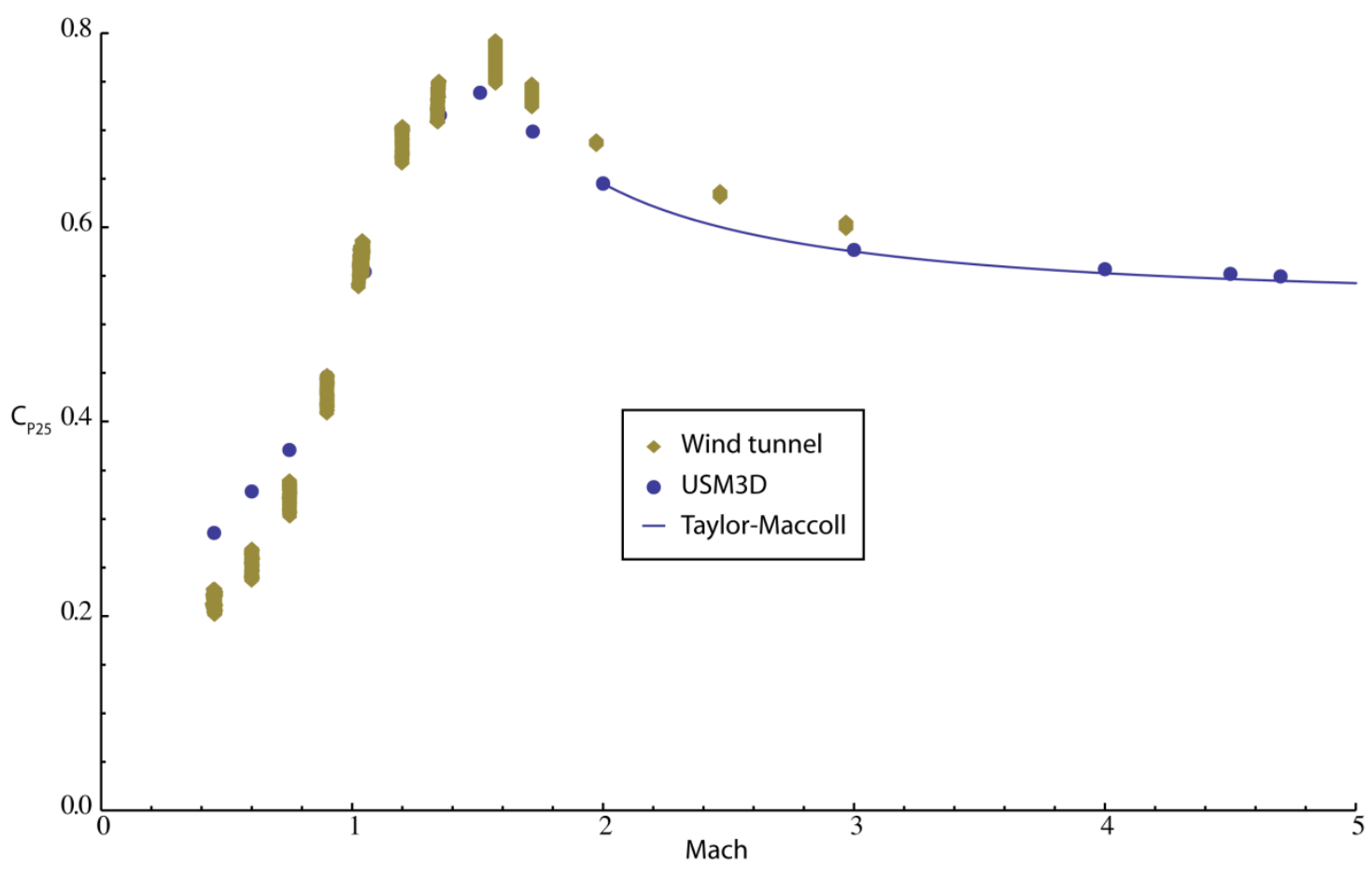

Figure 6. Comparison of CFD with wind tunnel testing shows $\mathrm{C}_{\mathrm{P} 25}$ compares moderately well at 0 angle of attack.

\section{Pressure coefficient of ports 2-5 at angle of attack}

This can be calculated easily with CFD. It can also be calculated using a modified version of the conical flow equations outlined by Sims [7], which is shown below. The 
expression for the pressure coefficient at the surface of the cone is expanded in powers of the angle of attack

$$
C_{P}=\left(C_{P}\right)_{\alpha=0}+\left(\frac{\partial C_{P}}{\partial \alpha}\right)_{\alpha=0} \alpha+\ldots
$$

The first term, $\left(C_{P}\right)_{\alpha=0}$, is found from the numerical solution to the Taylor-Macoll differential equation [6] for conical flow. The second term can be found using the numerical technique outlined by Sims [7]. Using this technique we may calculate $C_{\alpha}$ and $C_{\beta}$ by

$$
\begin{aligned}
& C_{\alpha}=\frac{C_{P 4}-C_{P 5}}{C_{P 1}-\frac{1}{4}\left(C_{P 2}+C_{P 3}+C_{P 4}+C_{P 5}\right)} \approx \frac{2}{C_{P 1}-\left(C_{P}\right)_{\alpha=0}}\left(\frac{\partial C_{P}}{\partial \alpha}\right)_{\alpha=0} \alpha, \\
& C_{\beta}=\frac{C_{P 2}-C_{P 3}}{C_{P 1}-\frac{1}{4}\left(C_{P 2}+C_{P 3}+C_{P 4}+C_{P 5}\right)} \approx \frac{2}{C_{P 1}-\left(C_{P}\right)_{\beta=0}}\left(\frac{\partial C_{P}}{\partial \beta}\right)_{\beta=0} \beta .
\end{aligned}
$$

These equations can be derived from equations $3,4,9$, and 11 . Here, $C_{P 1}$ is given by Equation 10. Equations 12 and 13 give an alternate method that does not depend on CFD and is valid for small angles and high Mach numbers. Figure 7 shows a comparison of the rate of change of $\alpha$ with respect to change of the coefficient, $C_{\alpha}$, and close agreement of the slopes between wind tunnel, CFD and Sims method provide confidence of calculating the pressure variations with angle of attack on ports 2-5. 


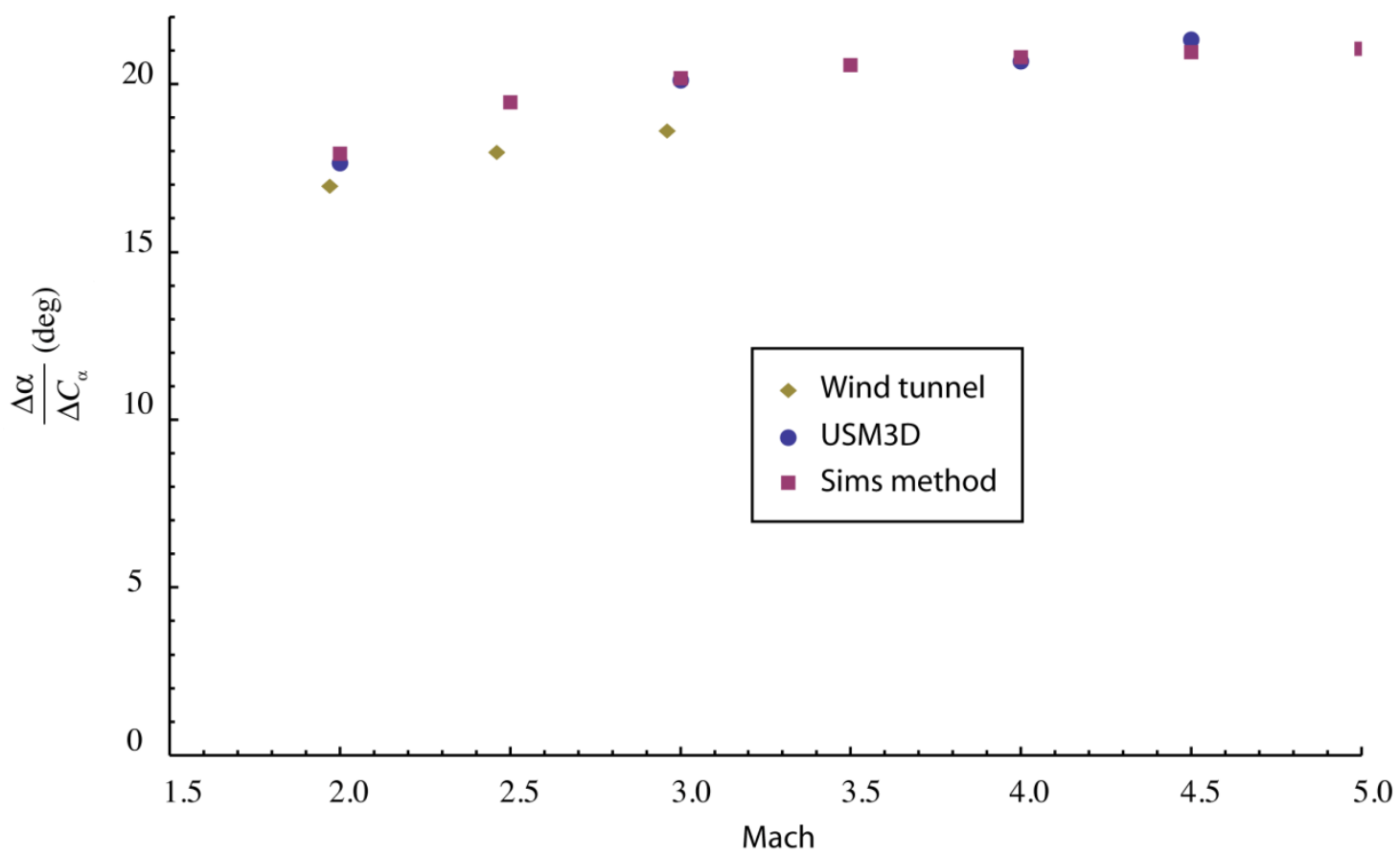

Figure 7. Rate of change of angle of attack with respect to $C_{\alpha}$ shows a very close agreement between CFD and the Sims method. It also shows good agreement with wind tunnel results. Note that Equation 10 was used to calculate $C_{P 1}$ in the USM3D plot.

\section{Mach coefficient}

Close agreement has been established between CFD and the Taylor-Maccoll differential equations. Both the pressure coefficient at the tip, $C_{P 1}$, and the average pressure coefficient between ports 2-5, $C_{25}$, have very little variation with respect to angle of attack at high Mach numbers. Therefore, using Equations 5 and 9 the Mach number coefficient can be defined as

$$
C_{M}=\frac{1}{2} \gamma M^{2} \frac{C_{P 1}-\frac{1}{4}\left(C_{P 2}+C_{P 3}+C_{P 4}+C_{P 5}\right)}{1+\frac{1}{2} \gamma M^{2} C_{P 1}} \approx \frac{1}{2} \gamma M^{2} \frac{C_{P 1}-\left(C_{P}\right)_{\alpha=0}}{1+\frac{1}{2} \gamma M^{2} C_{P 1}} .
$$

The result of applying equation 14 and comparing results from wind tunnel, CFD and theoretical approaches is shown in Figure 8. 


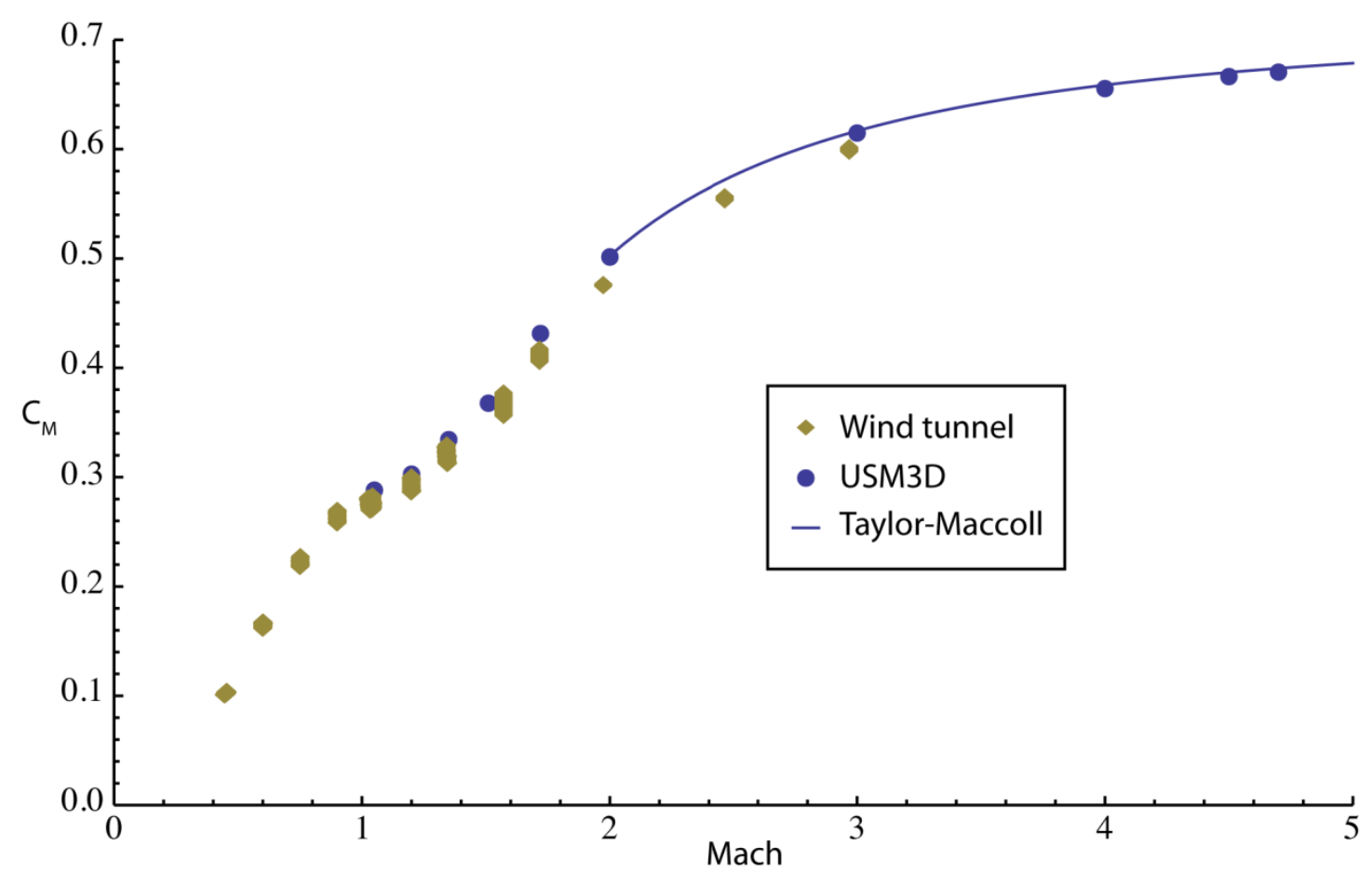

Figure 8. Mach coefficient shows a very close agreement between CFD and the TaylorMaccoll solution and good agreement with wind tunnel results. Note that Equation 10 was used to calculate $C_{P 1}$ in both the Taylor-Maccoll and the USM3D plot.

\section{Calibration results}

To complete the 5HP calibration, data missing from the wind tunnel test (above Mach $=$ 3.0) needs to be filled in. The important quantities are the coefficients $C_{\alpha}, C_{\beta}$, and $C_{M}$. There are two things one must take into account. First, the measured data has bias offsets. The second thing is that the calculated curves from either Taylor-Maccoll, Sims, CFD or other methods are not perfect matches and in order for the polynomial fits represented by Equation 6-8 to work with a minimum amount of terms, the data should be as contiguous as possible. Therefore, a linear transformation is applied to result in a more contiguous set of data. The transformation is accomplished as shown in equation 15.

$$
A\left(\begin{array}{l}
C_{\alpha} \\
C_{\beta}
\end{array}\right)_{\text {theoretical }}+B=\left(\begin{array}{c}
C_{\alpha} \\
C_{\beta}
\end{array}\right)_{\text {measured }} .
$$

$\mathrm{A}$ is a matrix and $\mathrm{B}$ is a vector that takes into account slight differences caused by measurement error. An optimal A and B can be found that minimizes the sum the square of the error between the left and right hand side of Equation 15 for each point where both measured and calculated data is available. This process minimizes the variance of the 
error and provides the least squares solution. This process is repeated in a similar fashion with $C_{M}$ except that $\mathrm{A}$ and $\mathrm{B}$ become scalers for that case. After determining $\mathrm{A}$ and $\mathrm{B}$, the transformed data can be used to fill in for the missing wind tunnel data. This process appears to give reasonable results. The resulting calibration curves for angle of attack and sideslip are shown in Figure 9, and for Mach number, Figure 10.

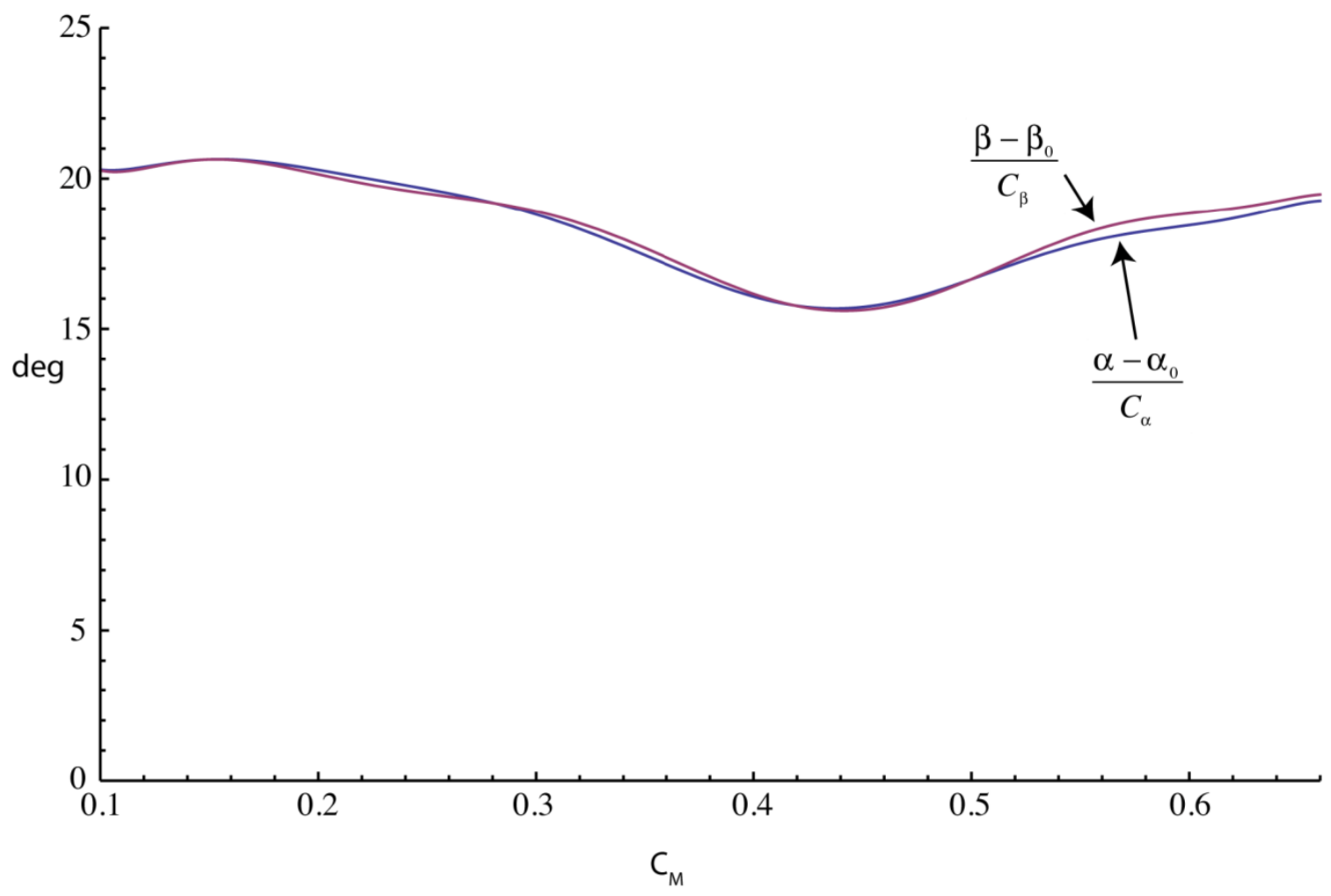

Figure 9. Calibration curve for $\alpha$ and $\beta$ as a function of $C_{M}$. 


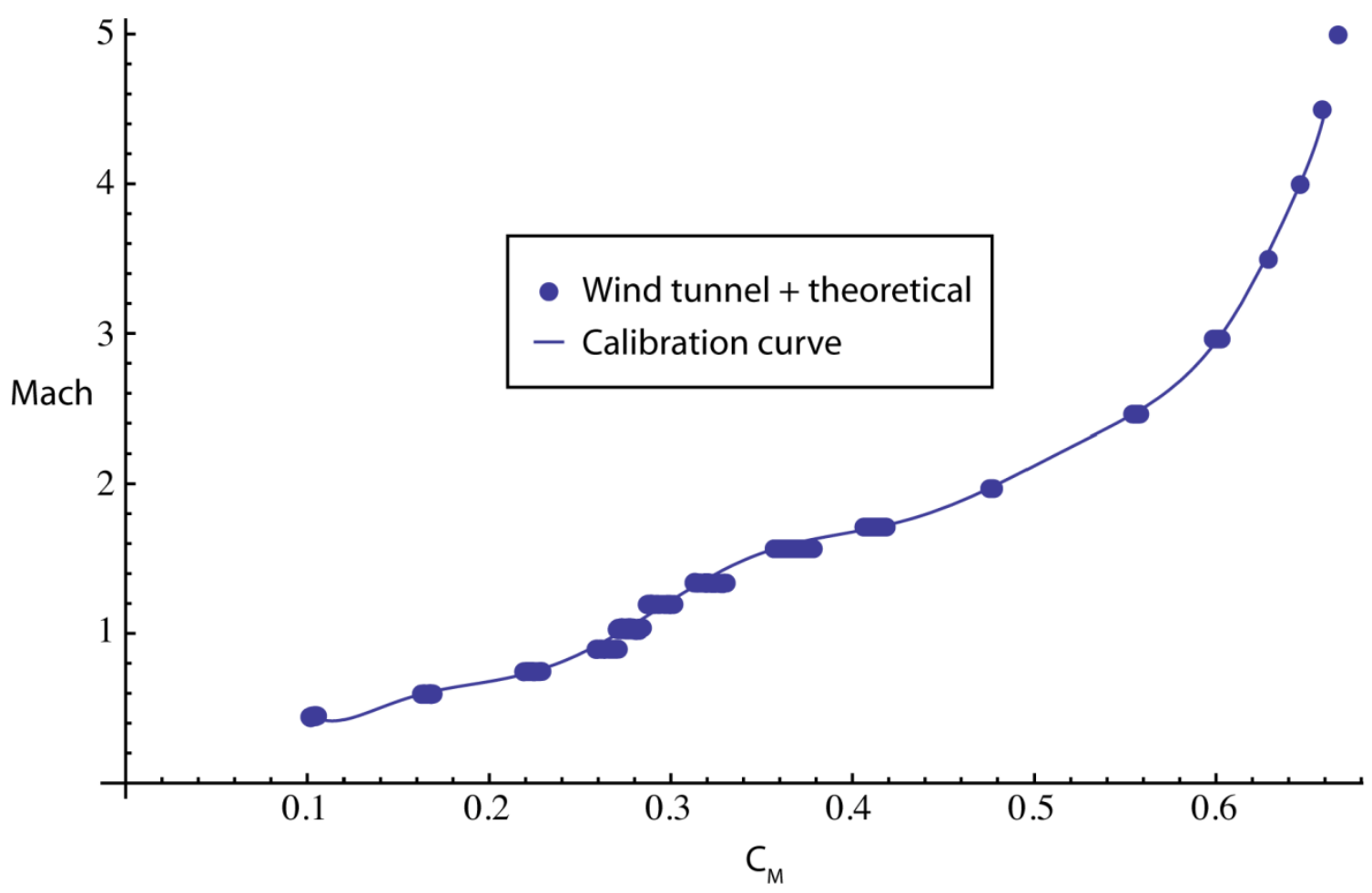

Figure 10. Mach number calibration curve plotted for $\alpha=\beta=0$.

\section{Flight data results}

\section{Flight data}

Plots of $\mathrm{C}_{\alpha}, \mathrm{C}_{\beta}$, and the vanes are shown in Figure 11. These comparisons show that the basic trend of the vanes compared to $\mathrm{C}_{\alpha}$ and $\mathrm{C}_{\beta}$ is similar but deviates near the end of the trajectory. The most probable cause is that moisture found its way inside the ports and boiled off in the upper atmosphere. That scenario fits both the added detail and deviation at the end of end of trajectory seen in the 5HP results. A second possible mechanism of introducing errors is "oil canning". Oil canning is an effect caused by lack of tensioning in the diaphragm of the pressure transducer when the differential pressure being measured is near zero. This is a manufacturing defect common to low/medium quality pressure transducers and varies from transducer to transducer. For all plots the launch time occurred at 110.5 seconds. 

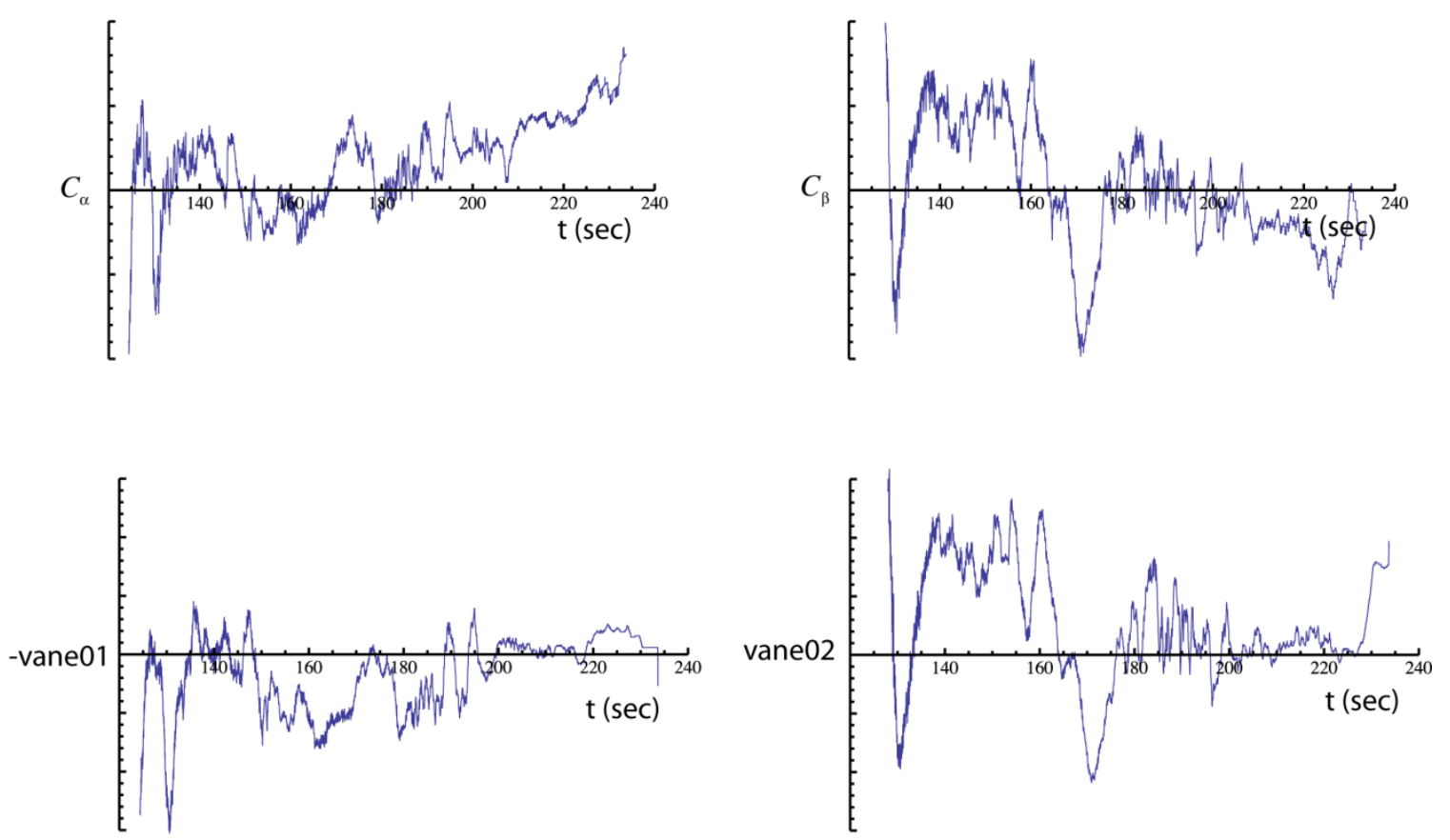

Figure 11. Comparison between $\mathrm{C}_{\alpha}, \mathrm{C}_{\beta}$, and the vanes shows basic trend deviates at end of trajectory (actual values withheld as they contain sensitive flight data).

$\mathrm{C}_{\mathrm{M}}$ is shown in Figure 12. This appears to be as expected both in range and trend. There is some roughness in the curve toward the end of the trajectory, however.

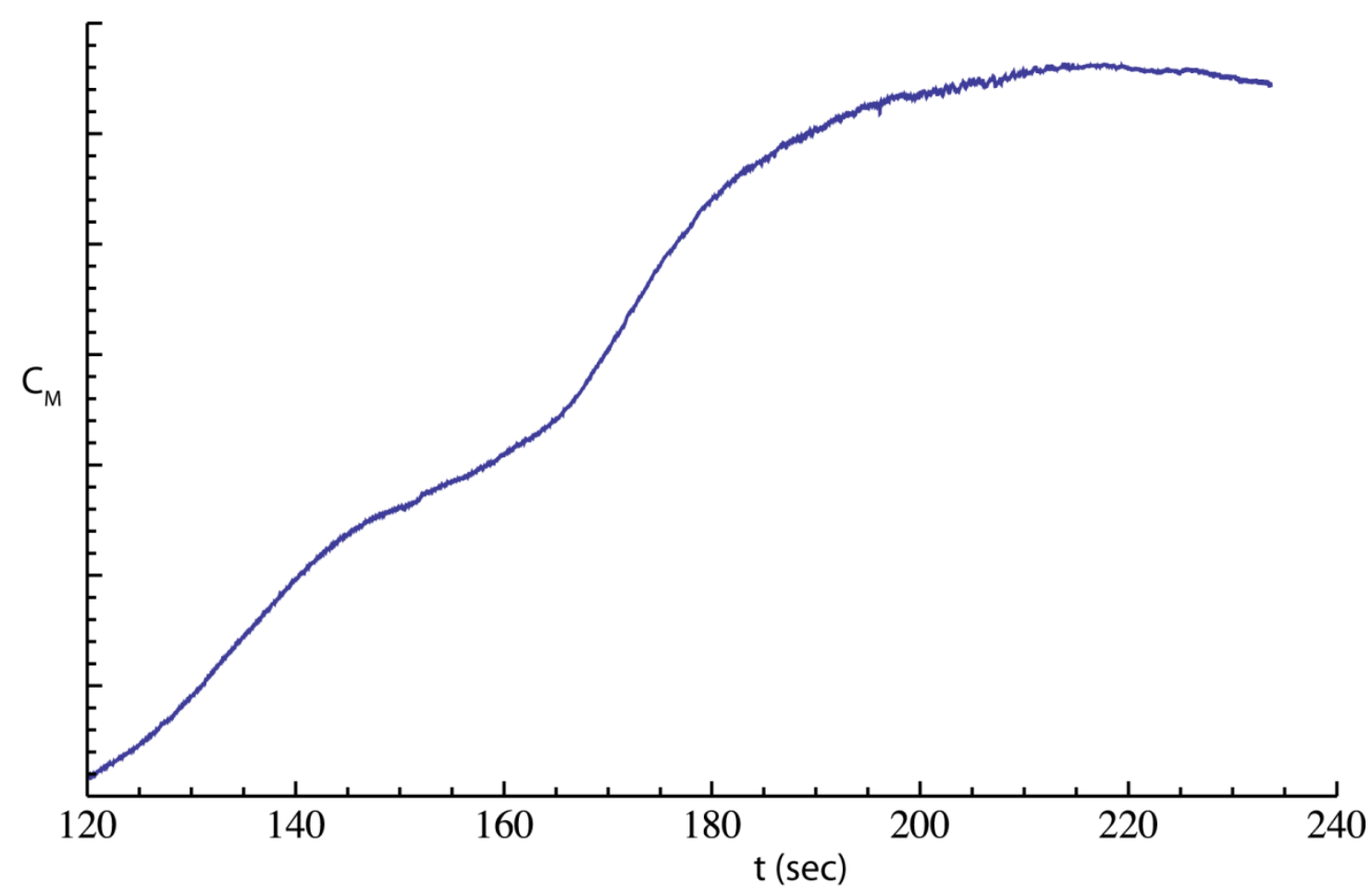


Figure 12. Plot of $\mathrm{C}_{\mathrm{M}}$ as a function of time (actual values withheld as they contain sensitive flight data).

\section{Calibrated Mach number results}

Estimates of Mach number are compute by direct application of $\mathrm{C}_{\alpha}, \mathrm{C}_{\beta}$, and $\mathrm{C}_{\mathrm{M}}$ calculated from the flight pressures applied to Equation 8. Figure 13 shows the results of this compared to the BET (best estimated trajectory) estimate, which was calculated from other sources.

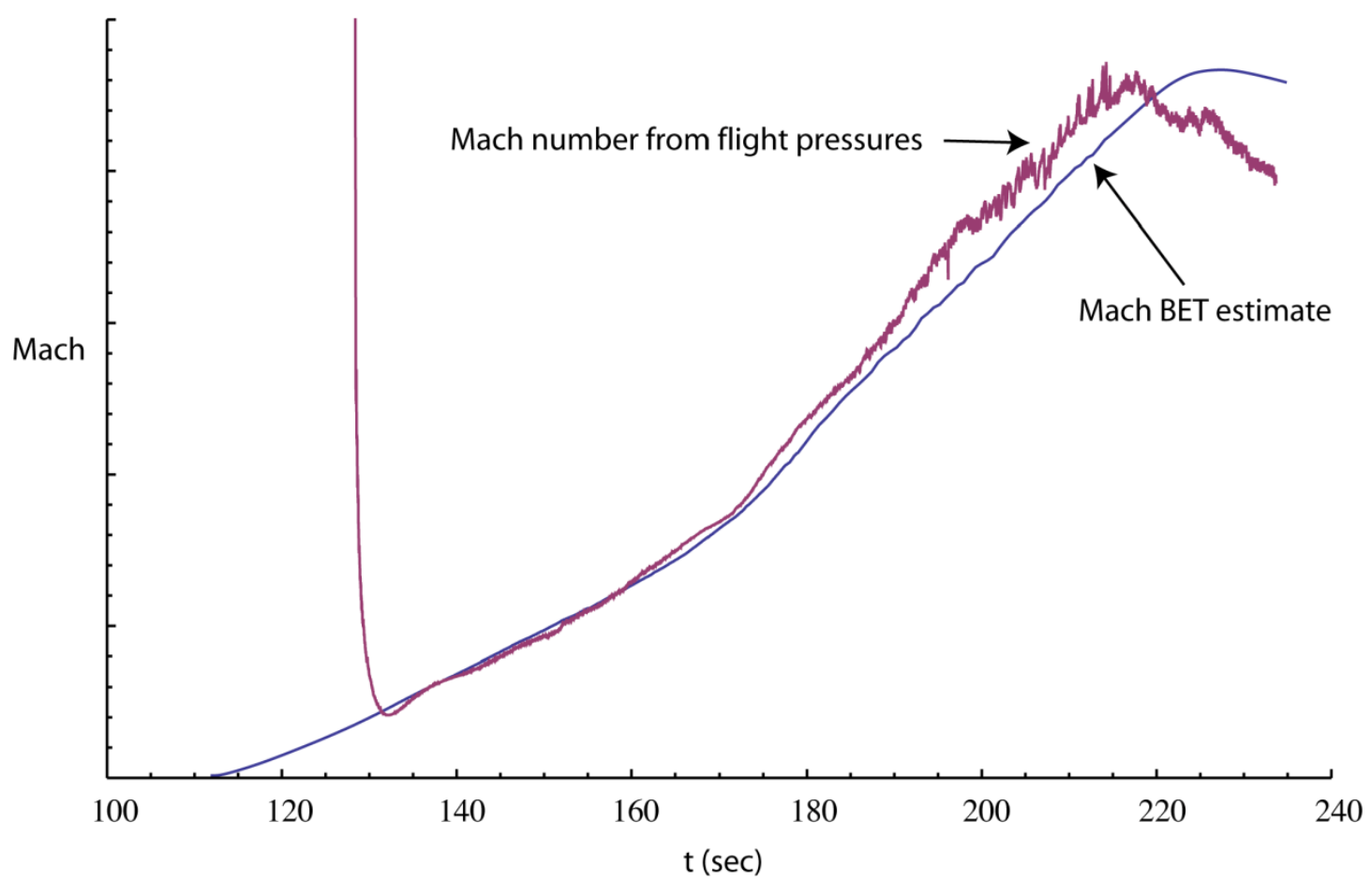

Figure 13. Mach number calculated from flight pressures vs. BET estimate (actual values withheld as they contain sensitive flight data).

\section{Calibrated angle of attack results}

A comparison of results from the vanes (corrected for upwash effects with CFD-derived corrections) and the angle of attack and sideslip from the 5HP using the calibrations described is shown in Figure 14. This comparison shows differences in the trends of the angle of attack and sideslip between the vane and probe data. 

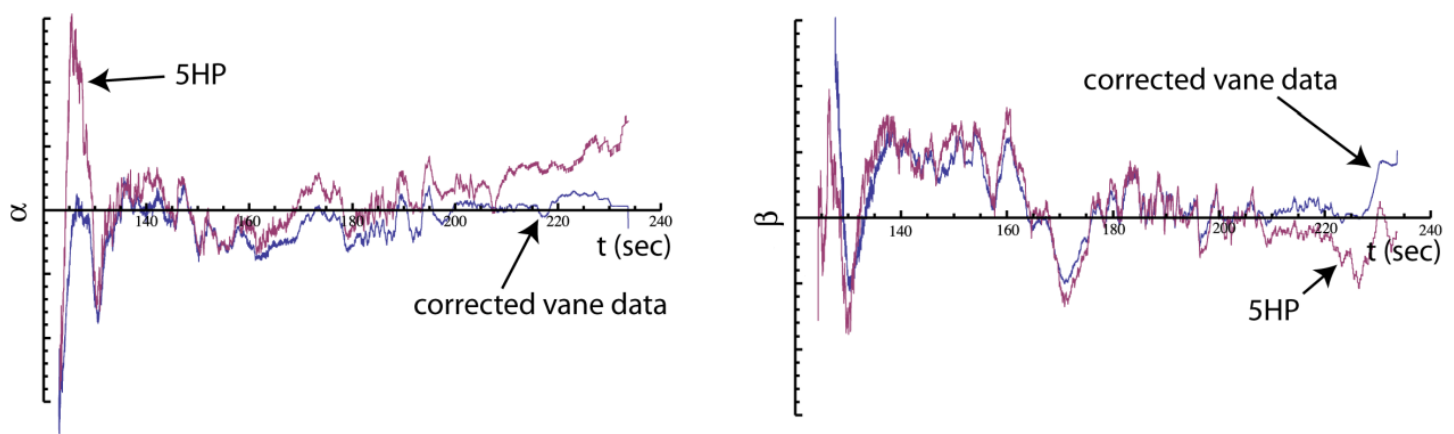

Figure 14. Angle of attack predicted by the vanes compared to that predicted by the probe shows differences in the trend (actual values withheld as they contain sensitive flight data).

\section{Analysis of results}

Aside from the obvious explanation of water in the $\alpha$ ports and pressure calibrations, "oil canning" was another possible explanation. Figure 15 shows one example of a possible oil canning event which occurs at a pressure zero crossing. The transducers could be in a non-linear region near zero differential pressure. What this nonlinear region creates is two equilibrium positions for the diaphragm at zero differential pressure and also is source for a hysteresis effects. However, upon close examination of the transducer calibration data there is no evidence for anomalous behavior at $\mathrm{P}=0$ on any transducer. As a result the oil canning hypothesis cannot be confirmed.

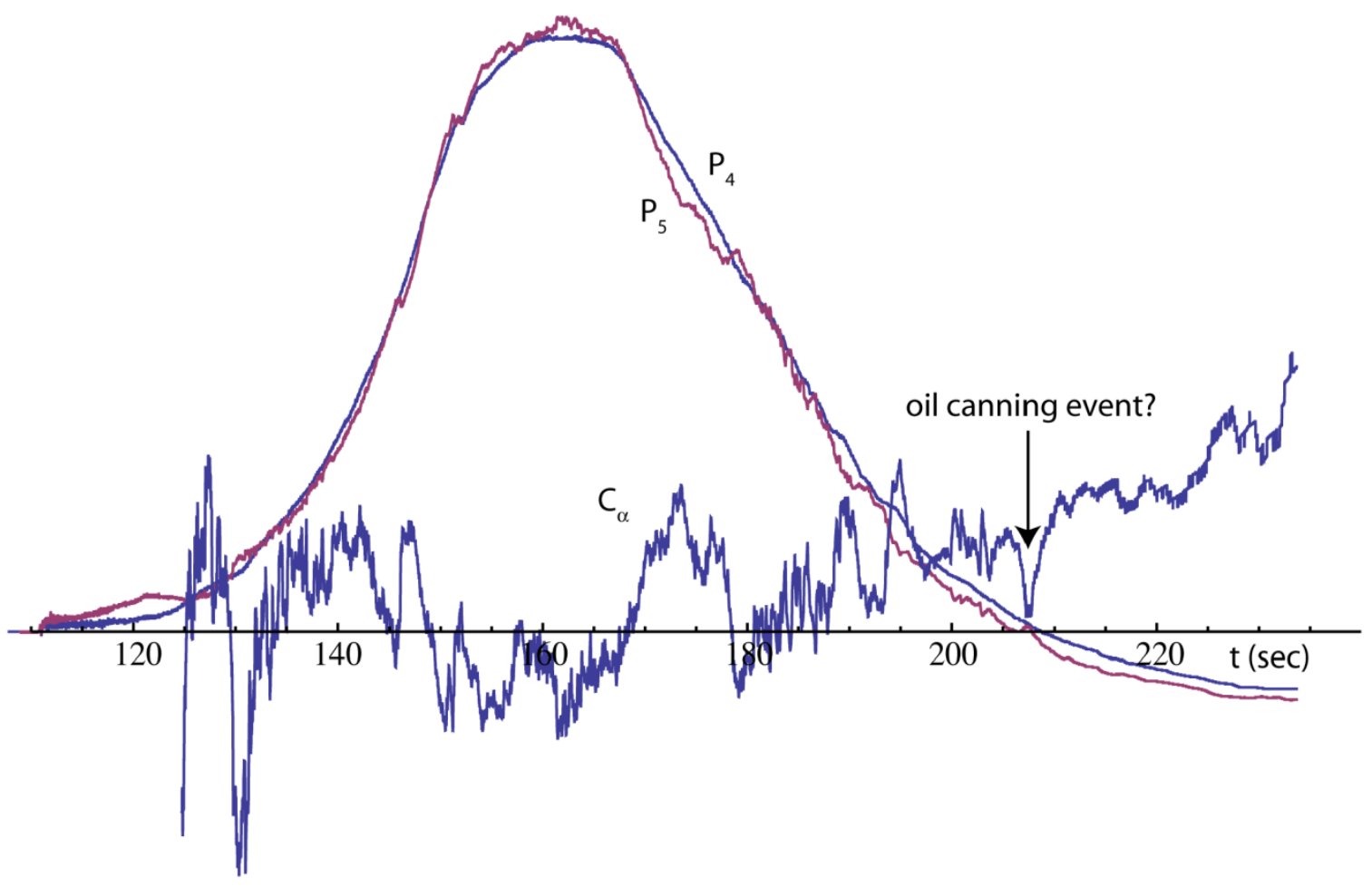


Figure 15. Plot of $\mathrm{P}_{4}, \mathrm{P}_{5}$, and $\mathrm{C}_{\alpha}$ shows one possible cause of error at the end of trajectory is "oil canning".

Further analysis was conducted to attempt to ascertain whether or not individual port data were compromised. The approach taken was to define $\mathrm{C}_{\alpha}$ and $\mathrm{C}_{\beta}$ using various combinations of ports. Figure 16 shows nearly identical results for 3 different definitions for $\mathrm{C}_{\alpha}$ using the wind tunnel data.

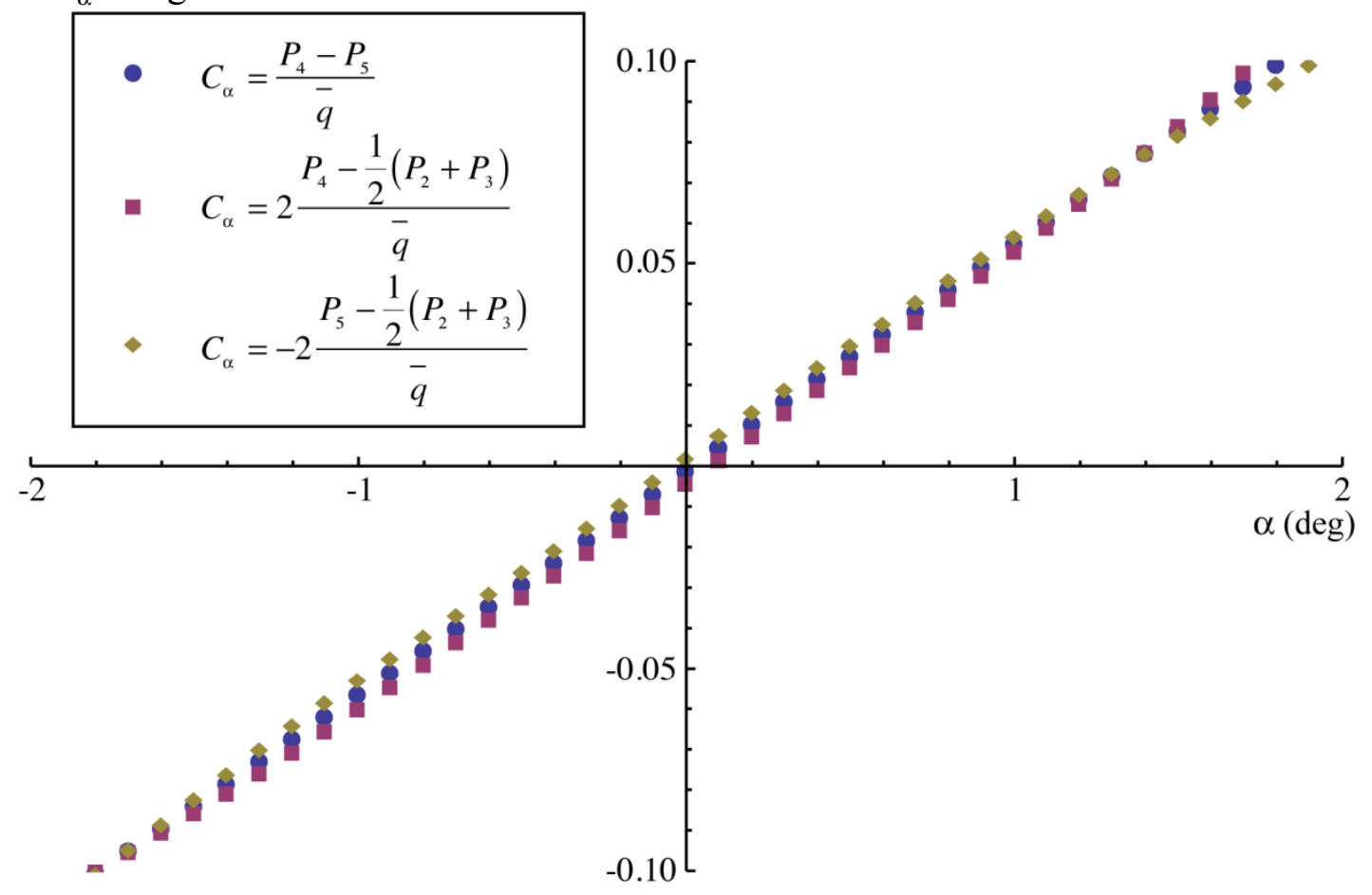

Figure 16. Standard definition of $\mathrm{C}_{\alpha}$ along with two alternate definitions show almost identical behavior in the wind tunnel.

The flight data, on the other hand, show large differences in results using the 3 different calculation approaches as shown in Figure 17. Because the second definition excludes $\mathrm{P}_{5}$ in the numerator and the third definition excludes $\mathrm{P}_{4}$ in the numerator, the flight results show there are now differences between the ports that did not exist during the acquisition of the calibration data in the wind tunnel. Some of these differences show sharp spikes and some show a deviation in the trend. This could be caused by water percolating out and vapor pressure caused by water boiling off in the upper atmosphere. Since the anomalous results are involving both ports, the 5HP instrument clearly has been seriously compromised. 


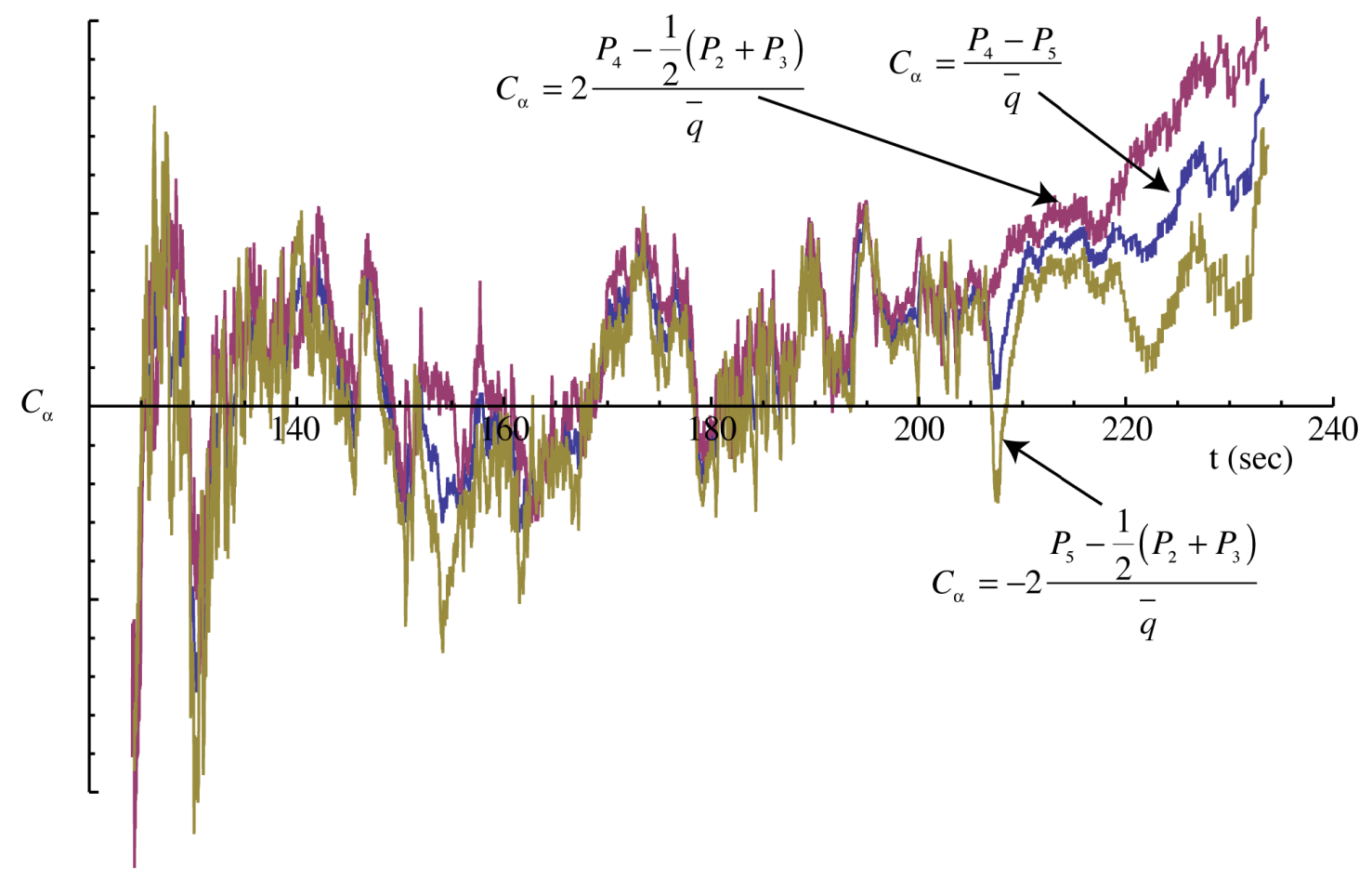

Figure 17. Flight data shows differences between ports that did not exist in the wind tunnel. Water percolation and vapor pressure are obvious explanations. Actual values withheld as they contain sensitive flight data.

\section{Conclusions}

The data from this instrument has been seriously compromised and should be considered unreliable. The Mach number estimates appear reasonable in the beginning of the trajectory but deviate as the flight progresses. The angle of attack ports (2-5) show differences that did not exist in the wind tunnel testing and the predicted angle of attack show very different behavior depending on which ports are used to do that calculation.

Significant work was conducted post-flight to complete the calibration of the probe. This effort demonstrated it is possible to use older analytical techniques such as the TaylorMaccoll differential equations for conical flow in conjunction with Sims method to help with the missing wind tunnel calibration data. For small angles and high Mach numbers the theoretical approaches compare well with CFD. The method fails below Mach 1.5, however, because that is where the shock front becomes detached. But since wind tunnel data was available up to Mach 3 this was not an issue, and the combination of wind tunnel and analytical techniques appeared to work well. The advantage of the analytic approaches vs. CFD approaches is in speed and the ability to do these calculations without the aid of a supercomputer. 


\section{Acknowledgment}

Many thanks to Steve Bauer for providing the USM3D CFD calculations and to Joseph Huwaldt for his helpful discussions. We would also like to thank Matt Zeiger and Brad Crawford for their contributions in collecting wind tunnel calibration data. 
Appendix

Flight pressure traces

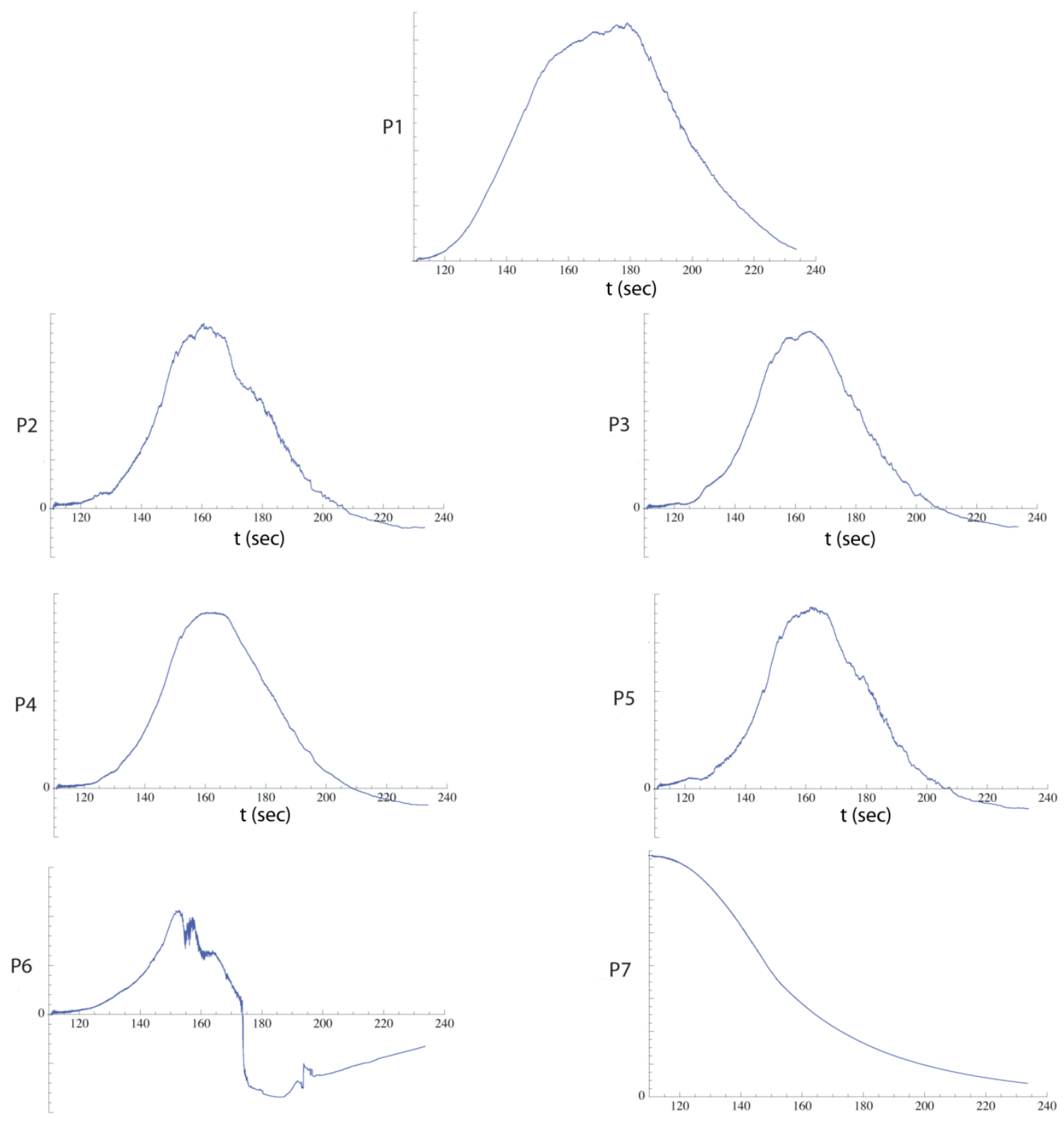

Figure A1. Flight pressures for 5-hole probe (actual values not shown because they contain sensitive flight data) 


\section{References}

[1] Milanovic, I. M. and Kalkhoran, I. M., "Numerical calibration of a conical five-hole probe for supersonic measurements", Meas. Sci. Technol. 11 (2000) 1812-1818. doi: $\underline{10.1088 / 0957-0233 / 11 / 12 / 322}$

[2] Gonsalez, J. C. and Arrington, E. A., "Five-Hole Flow Angle Probe Calibration for the NASA Glenn Icing Research Tunnel", NASA CR-1999-202330, 1999

[3] Anderson, J. D., Modern Compressible Flow, McGraw-Hill, New York, 1982, ISBN 0-7-001654-2, Chapter 3

[4] Liepmann, H. W. and Roshko, A., Elements of Gasdynamics, Dover Publications, 1957, pp. 149

[5] Anderson, J. D., Hypersonic and High Temperature Gas Dynamics, AIAA, 2000, ISBN 156347459X, pp. 61

[6] Anderson, J. D., Modern Compressible Flow, McGraw-Hill, New York, 1982, ISBN 0-7-001654-2, Chapter 10

[7] Sims, J. L., "Supersonic flow around right circular cones at small angles of attack", NASA-SP-3007, 1964 